\title{
Improving the permeability and adsorption of phenol by organophilic clay in clay liners
}

\author{
Nima Heidarzadeh ${ }^{\dagger}$, Paria Parhizi \\ Department of Civil Engineering, Faculty of Engineering, Kharazmi University, No. 43 South Mofatteh Ave, Tehran, Iran
}

\begin{abstract}
The aim of this study is to investigate the effect of five different combinations including: sand $70 \%$, bentonite $30 \%\left(\mathrm{~S}_{70} \mathrm{~B}_{30}\right)$ - sand $80 \%$, bentonite $20 \%\left(\mathrm{~S}_{80} \mathrm{~B}_{20}\right)$ - sand $80 \%$, organophilic $20 \%\left(\mathrm{~S}_{80} \mathrm{M}_{20}\right)$ - sand $60 \%$, bentonite $20 \%$, organophilic $20 \%\left(\mathrm{~S}_{60} \mathrm{~B}_{20} \mathrm{M}_{20}\right)$ and sand $75 \%$ - bentonite $15 \%$ - organophilic $10 \%\left(\mathrm{~S}_{75} \mathrm{~B}_{15} \mathrm{M}_{10}\right)$ on landfill linear structure in order to decrease phenol leaching. Hydraulic conductivity and adsorption behavior of the samples were investigated. The results demonstrated that the lowest hydraulic conductivity coefficient $\left(1.16 \times 10^{-11} \frac{\mathrm{m}}{\mathrm{s}}\right)$ was obtained for $\mathrm{S}_{70} \mathrm{~B}_{30}$. Furthermore, adding more than $20 \%$ of bentonite had no significant effect on reducing permeability. Moreover, Freundlich isotherm was introduced as the best model explaining adsorption behaviour due to its highest determination coefficient (0.945). The best samples for adsorption capacity of phenol and for both permeability and adsorption are $S_{80} M_{20}$ and $S_{60} B_{20} M_{20}$, respectively. Although the presence of bentonite was effective in reducing hydraulic conductivity, organic clay had no considerable impact on reducing permeability. Though, it's an exceptional role in adsorbing organic contaminants including phenol cannot be ignored. To meet all regulatory constraints, the optimal compound is made up of $10.2 \%$ of bentonite and $2.8 \%$ of organophilic clays with a minimized cost of 13.64 (\$/ton).
\end{abstract}

Keywords: Adsorption capacity, Dispersion coefficient, Hydraulic conductivity, Landfill liner, Organophilic clay

\section{Introduction}

Landfilling of the wastes is the most well-known process to prevent the harmful impacts of the contaminants dispersion in most countries. The major negative effect of landfills is leachate producing which contains a wide range of hazardous environmental contaminants. It can change physico-chemical properties of groundwater through infiltration to bottom layers.

To protect groundwater resources, the landfill site is usually designed by compressed clay liners or geo-membranes. There are several criteria recommended for the evaluation of liners performance regarding contamination movement control. In this regard, minimizing permeability and dispersion coefficients of the contaminants are the most important ones [1]. Diffusion involves the movement of a chemical from a region with higher concentration to the lower one. Based on the standards of the United States Environmental Protection Agency (U.S. EPA), the permeability of liners should be lower than $10^{-7} \mathrm{~cm} / \mathrm{s}$. Even with such hydraulic conductivity, the dispersion of organic contaminants from clay liners can be significant. Using absorbents in the landfill liners structure can reduce contaminants' dispersion through the retardation mechanism. The retardation factor (R) illustrates the effect of retarding the transfer of pollutant in the adsorption process. The adsorption level of organic contaminants by natural soil and clay depends on their solubility and the organic carbon content [2]. In organophilic (modified) clay, ion exchange process leads to convert ordinary bentonite to modified one. In this process, inorganic ions present in the double layer of ordinary bentonite such as sodium, calcium, magnesium are replaced by organic-based cation compounds like the quaternary ammonium salts (QAS). These changes convert the bentonite property from hydrophilic to organophilic (hydrophobic) that makes it suitable to absorb hydrocarbon. The organic contaminant adsorption capacity of organoclay increases with the increase in the number of carbons associated with the QAS. In previous studies, it had been stated that contaminant advection rate as well as dispersion rate will decrease considerably with the increase of the adsorption capacity in liner by organophilic clay without any need of raising the liner thickness
This is an Open Access article distributed under the terms of the Creative Commons Attribution Non-Commercial License (http://creativecommons.org/licenses/by-nc/3.0/) which permits unrestricted non-commercial use, distribution, and reproduction in any medium, provided the original work is properly cited.

Copyright (C) 2020 Korean Society of Environmental Engineers
Received November 13, 2018 Accepted February 13, 2019

${ }^{\dagger}$ Corresponding author

Email: n.heidarzadeh@khu.ac.ir

Tel: +98-21-88830891 Fax: +98-21-88830891

ORCID: 0000-0002-3130-407X 
$[3,4]$. Several studies have been conducted on the factors affecting the permeability and adsorption for different compounds. Daniel [5] indicated that in a mixture of sand and bentonite, hydraulic conductivity decreases significantly while the percentage of bentonite increase from 0 to $8 \%$ in a way that it's amount reduces from $10^{-4}$ to $10^{-8} \mathrm{~cm} / \mathrm{s}$. He also observed that less reduction occurs in hydraulic conductivity when the amount of bentonite was increased. Investigation of adsorption isotherm of organic compounds on ordinary bentonite and organophilic clays shows that the absorption of benzene, toluene, ethylbenzene and xylene by organophilic clay were $75 \%, 87 \%, 89 \%$ and $89 \%$ on average, respectively [6]. Irene [7] was examined five different percentages of bentonite and organophilic clays. The results revealed that sample containing $20 \%$ bentonite and $20 \%$ organophilic clays had the lowest permeability $\left(10^{-8} \mathrm{~cm} / \mathrm{s}\right)$. In addition, the best adsorption of Total Organic Carbon (TOC) was obtained for sample containing $20 \%$ organophilic clay and $80 \%$ sand. Jhamnani [2] also reported a permeability of $1.6 \times 10^{-8} \mathrm{~cm} / \mathrm{s}$ for a sample with $20 \%$ bentonite, $20 \%$ organophilic clay and $60 \%$ sand. He also asserted that the highest adsorption capacity of TOC was allocated to a sample with $15 \%$ bentonite, $10 \%$ organophilic clay and $75 \%$. Moreover, Sharafi and Bazigar [8] showed that the adsorption capacity of organophilic clay is evidently greater than that of ordinary clay. The results indicated the adsorption capacity of hydrocarbons (Crude oil, Kerosene, Gasoline and Toluene) range from 4 to 10 g/g of adsorbent [8]. In another study, Abdelwahab [9] measured the removal of contaminants in four adsorbents including activated carbon, bentonite, modified activated carbon, and organophilic bentonite. His evaluation on the effect of $\mathrm{pH}$, contact time, and contaminant concentration led to the discovery of the fact that the removal efficiencies of hydrocarbons (diesel) are $67-90 \%$ and 75-99.3\% for modified activated carbon and modified bentonite, respectively. Guddada [10] stated that not only the minimum bentonite required in the reduction of hydraulic conductivity is at least $12 \%$, but also he also believed that the saturated hydraulic conductivity of the mixture of sand and bentonite reduces with the increase in bentonite content. In this study, the best result of permeability was obtained for a sample with $15 \%$ bentonite and $85 \%$ sand. Sarkar et al. [11] studied the adsorption capacity of ordinary bentonite (Witheroo Bentonit) and HW2CEC (Witheroo Bentonite modified by hexadecyl trimethyl ammonium). Comparing ordinary bentonite $(0.19 \mathrm{mg} / \mathrm{kg})$ and organophilic $(11.79$ $\mathrm{mg} / \mathrm{kg}$ ), revealed an increase in phenol adsorption. It was probably because of the modification by long chain organic compounds. Badv and Ashrafi [1] revealed that the sample containing 40\% of bentonite and $60 \%$ of sand has the lowest permeability (1.91 $\times 10^{-11} \mathrm{~m} / \mathrm{s}$ ) and the addition of bentonite more than $20 \%$ does not present a significant effect in reducing permeability as all pores are filled due to swelling of the bentonite. Sharafi et al. [12] compared the adsorption of organic compounds in ordinary and organophilic clays. The results show that adsorption of organophilic clay for gasoline and toluene ( $9 \mathrm{~g} / \mathrm{g}$ ) has been almost twice more than kerosene (4.8 g/g). Moreover, the amount of hydrocarbon adsorption on organophilic clay is equivalent to five times of its own weight. While the adsorption capacity of ordinary clay has been reported to be 5 (for toluene) to 8 times (for kerosene and gasoline) lower than organophilic clay.

The application of the organo-clay in the landfill liners has been also investigated in the recent researches. This Zhao et al. [13] reviewed several properties of organoclays including the fundamental behavior of organoclays, focusing on geochemical properties such as electrokinetic potential, hydrophobicity, sorptivity, adsorption of nonpolar compounds and electrical conductivity, hydraulic conductivity, strength, thermal stability and thermal conductivity. Moreover, Javadi et al. [14] carried out several laboratory tests to examine the swelling, permeability and contaminant retention of compacted silty clay amended with an organoclay (hexa decyl trimethyl ammonium (HDTMA) modified bentonite) against both gasoline and organic solution. The swelling properties and the hydraulic conductivities of compacted soils with varying liquids were evaluated and the transport of naphthalene and a possible component of NAPLs was examined through batch sorption and column tests. The results indicated that the addition of 10\% HDTMA bentonite to compacted silty clay slightly increased the permeability of the mixture to water. However, higher swelling tendency and lower permeability to gasoline were also observed. With $5 \%$ of HDTMA bentonite amendment, the compacted silty clay soil had a much stronger retardation capacity for naphthalene [14]. Gitipour et al. [15] also studied the effect of using an organo-caly on the geosynthetic clay liners (GCLs). Results of XRD analysis for modified bentonite samples indicated an increase of $63.2 \%$ in interlaminar spacing after exposure to the crude oil comparing ordinary bentonite with only $0.5 \%$ increase. Moreover, modified bentonites showed lower permeability $\left(5.2 \times 10^{-9} \mathrm{~cm} / \mathrm{s}\right)$ that the ordinary bentonites $\left(1.2 \times 10^{-6} \mathrm{~cm} / \mathrm{s}\right)$ against crude oil. They conclude using of modified clays instead of ordinary clays in the GCLs structure is more viable [15]. Zhu et al. [16] investigated organo-clays (OCs) as sorbents of hydrophobic organic contaminants. After studying OCs structure, they evaluated the sorptive characteristics of the OCs. They showed the effect of layer charge on the sorption of benzene by two different modified montmorillonites with low and high charge characteristics. In this research, sorption isotherms of several samples were also investigated.

In the present research, phenol $\left(\mathrm{C}_{6} \mathrm{H}_{5} \mathrm{OH}\right)$ was used as an organic contaminant. Phenol and its derivatives are used in a variety of industries including oil refineries, petrochemical industry, mines, and pesticides. Through unsafe discharge of the wastewater of these industries, they cause environmental contamination. The effects resulted from being exposed to phenol are associated with adsorption amount and contact time which varies from inflammation and skin burning to toxicity along with reduced blood pressure, increased heart beats, and coma.

Despite the researches have been carried out on influencing factors on the permeability of compounds such as bentonite, a limited number of studies has been conducted in the field of the best combination of bentonite and organophilic clays to enhance the adsorption and permeability of liners. The aim of this research is to investigate the effect of using organophilic clay on reducing phenol transfer and achieving the best result for the permeability coefficient and adsorption. In this regard, experiments were carried out on permeability, adsorption, and dispersion coefficient of five samples containing different percentages of organophilic clay, sand and bentonite in order to examine the effect of the addition of organophilic clay as an adsorbent to clay liner. 


\section{Materials and Methods}

\subsection{Materials}

In this study, ordinary clay (sodium-bentonite), organophilic clay, sand and phenol were used as organic pollutants.

Bentonite soil was prepared through a bentonite mine located in Kashan province, Iran. The used organophilic clay was purchased from the office of "Southern Clay Products" in china, although the factory was located in the USA. This product is offered under the commercial name of Clayton ${ }^{\circledR}$ 40. The organophilic clay used is the same as Montmorillonite modified with the quaternary ammonium salt under the chemical name of dimethyl di(hydrogen) thalo [17]. Physical and chemical properties of organophilic clay and bentonite are presented in Table 1.

Table 1. Chemical and Physical Specifications of Organophilic Clay and Bentonite Used in Tests

\begin{tabular}{|c|c|c|c|}
\hline & Specifications & $\begin{array}{c}\text { Organophilic } \\
\text { clay [17] }\end{array}$ & $\begin{array}{c}\text { Bentonite } \\
{[18]}\end{array}$ \\
\hline \multirow{10}{*}{$\begin{array}{l}\text { Chemical } \\
\text { properties }\end{array}$} & $\mathrm{SiO}_{2}(\%)$ & 42.6 & 71.5 \\
\hline & $\mathrm{Al}_{2} \mathrm{O}_{3}(\%)$ & 14.1 & 12.45 \\
\hline & $\mathrm{MgO}(\%)$ & 1.5 & 1.35 \\
\hline & $\mathrm{Fe}_{2} \mathrm{O}_{3}(\%)$ & 3.1 & 1.49 \\
\hline & $\mathrm{CaO}(\%)$ & 0.2 & 1.21 \\
\hline & $\mathrm{Na}_{2} \mathrm{O}(\%)$ & 0.3 & 2.03 \\
\hline & $\mathrm{k}_{2} \mathrm{O}(\%)$ & 0.1 & 0.55 \\
\hline & $\mathrm{TiO}_{2}(\%)$ & 0.1 & $0.1>$ \\
\hline & $\mathrm{SO}_{3}(\%)$ & - & 0.39 \\
\hline & $\begin{array}{c}\text { Loss on ignition at } \\
1,000^{\circ} \mathrm{C}\end{array}$ & 38.5 & 8.80 \\
\hline \multirow{4}{*}{$\begin{array}{l}\text { Physical } \\
\text { properties }\end{array}$} & Color & Light cream & Light cream \\
\hline & Specific gravity & 1.7 & 2.75 \\
\hline & $\begin{array}{l}\text { Cation exchange } \\
\text { capacity } \\
\text { (CEC, meq/100 g) }\end{array}$ & 95 & 105-95 \\
\hline & Water content & 2 & 4 \\
\hline
\end{tabular}

Phenol, the organic contaminant, was supplied by Merck Co. with $99 \%$ purity. Accurate specification of phenol are density 1.07 $\mathrm{g} / \mathrm{cm}^{3}$, solubility $84 \mathrm{~g} / \mathrm{L}$ and $\mathrm{pH}\left(20^{\circ} \mathrm{C}\right) 5[19]$.

\subsection{Analytical Methods}

In this research, five samples were prepared to evaluate the degree of adsorption, hydraulic conductivity (permeability), and dispersion coefficient as shown in Table 2.

\subsubsection{Compaction test}

The standard Proctor compaction test was carried out based on ASTMD-698 on the samples in order to determine the optimum moisture content (OMC). To achieve permeability, determining optimum moisture is crucial. Studies have shown that soils com- pacted in OMC had a lower permeability. Thus, the samples were compacted in moisture content of $3 \%$ greater than the obtained OMC to achieve the minimum permeability [20, 21].

Table 2. Specification of the Samples Examined in the Study

\begin{tabular}{cccc}
\hline \multirow{2}{*}{ Sample name } & \multicolumn{3}{c}{ Percent of components in the samples } \\
\cline { 2 - 4 } & $\mathbf{B}^{\mathbf{a}} \mathbf{( \% )}$ & $\mathbf{M}^{\mathbf{b}}(\mathbf{\%})$ & $\mathbf{S}^{\mathbf{c}}(\mathbf{\%})$ \\
\hline $\mathrm{S}_{70} \mathrm{~B}_{30}$ & 30 & 0 & 70 \\
$\mathrm{~S}_{80} \mathrm{~B}_{20}$ & 20 & 0 & 80 \\
$\mathrm{~S}_{80} \mathrm{M}_{20}$ & 0 & 20 & 80 \\
$\mathrm{~S}_{60} \mathrm{~B}_{20} \mathrm{M}_{20}$ & 20 & 20 & 60 \\
$\mathrm{~S}_{75} \mathrm{~B}_{15} \mathrm{M}_{10}$ & 15 & 10 & 75 \\
\hline
\end{tabular}

B: Na-Bentonite, M: Organophilic clay, S: Sand

2.2.2. Batch equilibrium absorption test and adsorption isotherm To investigate the adsorption capacity of the organic contaminant by the organophilic clay, a batch equilibrium adsorption test was performed. First, 5-13 g of phenol was dissolved in $60 \mathrm{~mL}$ of water. Then, 1:10 ratio of organophilic clay was added to the aqueous solution. After that, it was mixed by an electrical shaker for 24 h. Finally, a centrifuge device with a rate of 3,000 rpm was applied for $15 \mathrm{~min}$ to separate liquid and solid phases [22].

The performance of adsorbent can be investigated by sorption isotherms including linear, Freundlich and Langmuir isotherms. In general, the sorption isotherm is a mathematical equation describing adsorption phenomenon at a constant temperature and $\mathrm{pH}$ as a valuable linear/nonlinear curve [23]. In this study, three mentioned isotherms were used by the following formulations [23]:

1) Linear isotherm

$$
q=k_{d} C
$$

2) Freundlich isotherm

$$
q=k_{f} c^{\frac{1}{n}}, \text { or }
$$

$$
\log q=\log k_{f}+\frac{1}{n} \log c
$$

3) Langmuir isotherm

$$
q=q_{m} \frac{K_{l} C_{e}}{1+K_{l} C_{e}}
$$

Where

$C$ is the concentration of the pollutant in solution at equilibrium $(\mathrm{mg} / \mathrm{L})$,

$q$ is the adsorbed materials per unit weight of the solid phase (adsorbent) at equilibrium (mg/g); $q_{m}$ is the maximum of $q$ (mg/g),

$K_{d}$ is the distribution coefficient,

$K_{L}$ is the Langmuir constant which is related to adsorption capacity and energy or net enthalpy of adsorption.

$K_{f}$ and $n$ are the constants of the Freundlich isotherm which depend on the adsorption capacity and intensity. 


\subsubsection{Sample preparation and analysis of phenol}

To enhance the accuracy of detection, all samples were diluted with a ratio of $1: 20$ by distilled water. A blank sample containing $100 \mathrm{~L}$ of distilled water was also applied. Then, $3 \mathrm{~mL}$ ammonium buffers (16.813 g of $\mathrm{NH}_{4} \mathrm{Cl}$ was added to $142.5 \mathrm{~mL}$ of concentrated ammonium and then, it was increased to a volume of $250 \mathrm{~mL}$ using distilled water), one $\mathrm{mL}$ of 4-amino anti pyrine and $1 \mathrm{~mL}$ potassium ferri- cyanide was added to both blank and contaminated samples. After calibration with the blank sample, the others were analyzed for phenol concentration using HACH LANGE spectrophotometer (DR 2800- Germany) by the U.S.EPA method 420.1 [24]. It was able to detect a wide range of pollutant concentration $(0.005$ $-5 \mathrm{mg} / \mathrm{L})$ at $510 \mathrm{~nm}$.

\subsubsection{Hydraulic conductivity}

To determine hydraulic conductivity, permeability test was conducted and calculated using the following equation was also used to calculate the coefficient of permeability in accordance with ASTM 5084-6 [25].

$$
k=2.3 \frac{a l}{A t} \log \left[\frac{h 1}{h 2}\right]
$$

Where,

$\mathrm{K}=$ Coefficient of permeability $(\mathrm{m} / \mathrm{s})$,

$\mathrm{a}=$ Area of the burette $\left(\mathrm{m}^{2}\right)$,

$\mathrm{L}=$ Length of soil column (m),

$\mathrm{A}=$ Area of the soil column $\left(\mathrm{m}^{2}\right)$,

$h_{1}=$ Primary height of water $(\mathrm{m})$,

$h_{2}=$ Secondary height of water $(\mathrm{m})$,

$\mathrm{t}=$ Time required to get head drop of $\Delta \mathrm{h}(\mathrm{s})$.

There are different opinions regarding the material of the permeameter wall. American Society for Testing and Materials (ASTM) recommends the use of the flexible wall for measuring hydraulic conductivity of fine-grained soils [26]. Additionally, Trainor [27] also suggests the flexible wall for performing the experiment. However, EPA in Method 9100 did not mention the material of the permeameter wall for determining the permeability of soil [28]. On the contrary, Sarsby et al. [29] propose the rigid wall for the permeameter. In addition, in another study, the use of rigid wall has also been proposed [30]. In this research, the samples were placed inside a mold with a rigid wall having a diameter of 10 $\mathrm{cm}$ and a height of $13 \mathrm{~cm}$. Thereafter, the solution containing the phenol concentration of $2,000 \mathrm{mg} / \mathrm{L}$ was added to the soil. After saturation of the sample, the outflowing solution from the device was collected to measure the phenol concentration.

\subsubsection{Molecular diffusion theory}

Molecular diffusion is a process in which constituent molecules or ions of compound transport in the direction of the concentration gradient in a solution. Molecular diffusion flux, $\mathrm{J}_{\mathrm{D}}$, is written as the following equation for steady-state conditions, as the first Fick's law [31].

$$
J_{D}=-D_{0} \frac{\partial c}{\partial x}
$$

where $J_{D}$ is the mass flux of solute $\left(\mathrm{M} / \mathrm{L}^{2} \mathrm{~T}\right), C$ is the solute concentration $\left(\mathrm{M} / \mathrm{L}^{3}\right), D_{o}$ is the free-solution diffusion coefficient $\left(\mathrm{L}^{2} / \mathrm{T}\right)$, and $\frac{\partial c}{\partial x}$ is the concentration gradient in the " $\mathrm{x}$ " direction.

In a porous media like soil, the molecular diffusion $\left(\mathrm{D}_{0}\right)$ of chemicals is lower than that free solution. Then, the Eq. (6) is modified by the effective diffusion coefficient $\left(D^{*}\right)$.

The Fick's first law is only applied for a free solution when the concentration gradient is constant over time. While Fick's second law assumed for transient transport. Fick's second law illustrates the rate of changes in the concentration over time and distance in a medium in which molecular diffusion occurs. It is expressed by the following equation [31]:

$$
\frac{\delta C}{\delta t}=\frac{D^{*}}{R} \frac{\delta^{2} C}{\delta x^{2}}
$$

Adding the advection mechanism and dispersion effect, as the final one-dimensional advection -dispersion equation is obtained as follows:

$$
1 / R\left(D_{x} \frac{\delta^{2} c}{\delta x^{2}}-V_{x} \frac{\delta c}{\delta x}\right)=\frac{\delta c}{\delta t}
$$

Where

$\mathrm{V}_{\mathrm{x}}=$ pore velocity in the $\mathrm{x}$ direction

$D_{X}$ is dispersion coefficient, includes two components of molecular diffusion and mechanical dispersion.

$R=$ retardation factor, where

$$
R=1+\frac{\rho_{b} \times K_{d}}{n}
$$

and $\mathrm{n}=$ porosity, $\rho_{\mathrm{b}}=$ bulk density, and $K_{d}$ is the distribution coefficient which is calculated by the following relation.

$$
K_{d}=f_{o c} \times K_{o c}
$$

Where, $f_{o c}$ is the organic carbon fraction of soil, $K_{o c}$ is the partition coefficient of a compound between organic carbon and water.

To solve Eq. (8), the following boundary and initial conditions were applied [31]:

$$
\begin{array}{lll}
C(x, t)=0 & \text { for } \mathrm{t}=0 & \text { and } \mathrm{x}>0 \\
C(x, t)=\mathrm{C}_{0} & \text { for } \mathrm{x}=0 & \\
C(x, t)=0 & \text { for } \mathrm{x}=\infty & \\
\text { the solution of Eq. (8) is } &
\end{array}
$$

$$
C(x, t)=\frac{C_{o}}{2}\left(\operatorname{erfc}\left(\frac{R X-V_{X} t}{2 \sqrt{R D_{x} t}}\right)+\exp \left(\frac{V_{x} X}{D_{x}}\right) \times \operatorname{erfc}\left(\frac{R X+V_{X} t}{2 \sqrt{R D_{x} t}}\right)\right)
$$

Where $C_{0}$ is the initial concentration of phenol $(2,000 \mathrm{mg} / \mathrm{L})$, $C$ is the output concentration, $\mathrm{t}=$ time and $\mathrm{x}=$ passing distance of the contaminants in the soil. By knowing the mentioned variables/parameter, $D_{x}$ can be estimated by a trial and error procedure.

After obtaining the dispersion coefficient, the sample with the lowest $D_{x}$ is chosen as the best combination in terms of dispersion. 


\subsubsection{Cost analysis to find the best combination}

To minimize the cost, Lingo software was used in order to find the optimal combination. Lingo is a comprehensive tool designed to solve linear, nonlinear, quadratic, quadratically constrained, second order cone, semi-definite, stochastic, and integer optimization models. An optimization model consists of three parts:

- Defining objective function: This is a single formula that accurately describes what model should be optimized. In this research, an objective function is minimizing cost by a linear optimization approach. The average cost of bentonite and organophilic clays were assumed to be 60 and 267.5 \$/ton, respectively [32].

- Selecting variables: In this research, the percentages of bentonite and organophilic clays were chosen as variables. The optimal value of the objective function can be determined by changing the variables.

- Defining constraints: These formulas define the limits on the values of the variables. The constraints are 1) permeability of less than $10^{-9} \mathrm{~m} / \mathrm{s}$ [33] and 2) allowable phenol leakage of less than $137 \mathrm{mg} / \mathrm{L}$ [34]. To define such constraints, the related functions were obtained from multiple regression analyses of the examined samples in Minitab software. Several functions were analyzed to reach the best correlation. The best formula was selected by its highest determination coefficient $\left(R^{2}\right)$.

\section{Results and Discussion}

\subsection{Sorption Isotherms}

The results of phenol adsorption on organophilic clay during the batch equilibrium test are demonstrated in Table 3. As shown in Fig. 1, Freundlich equation has better fit than other isotherms. It can be explained by the equation $S=10.7 \times 10^{-4} \mathrm{C}^{1.25}$.

Sarkar et al. [11], Belarbi and Al-Malack [35], and Froehner et al. [36] also achieved similar results in their researches on organophilic clay and considered the Freundlich isotherm as suitable.

Since negative values in Langmuir adsorption isotherm obtained, Maarof et al. [37] pointed out it is not an appropriate model to describe phenol adsorption on modified Montmorillonite. However, Banat et al. [38] introduced both Freundlich and Langmuir adsorption isotherms as suitable for adsorption of phenol on bentonite. Djebbar et al. [39] compared adsorption isotherm on bentonite and organophilic clays. They were given Langmuir isotherm, as
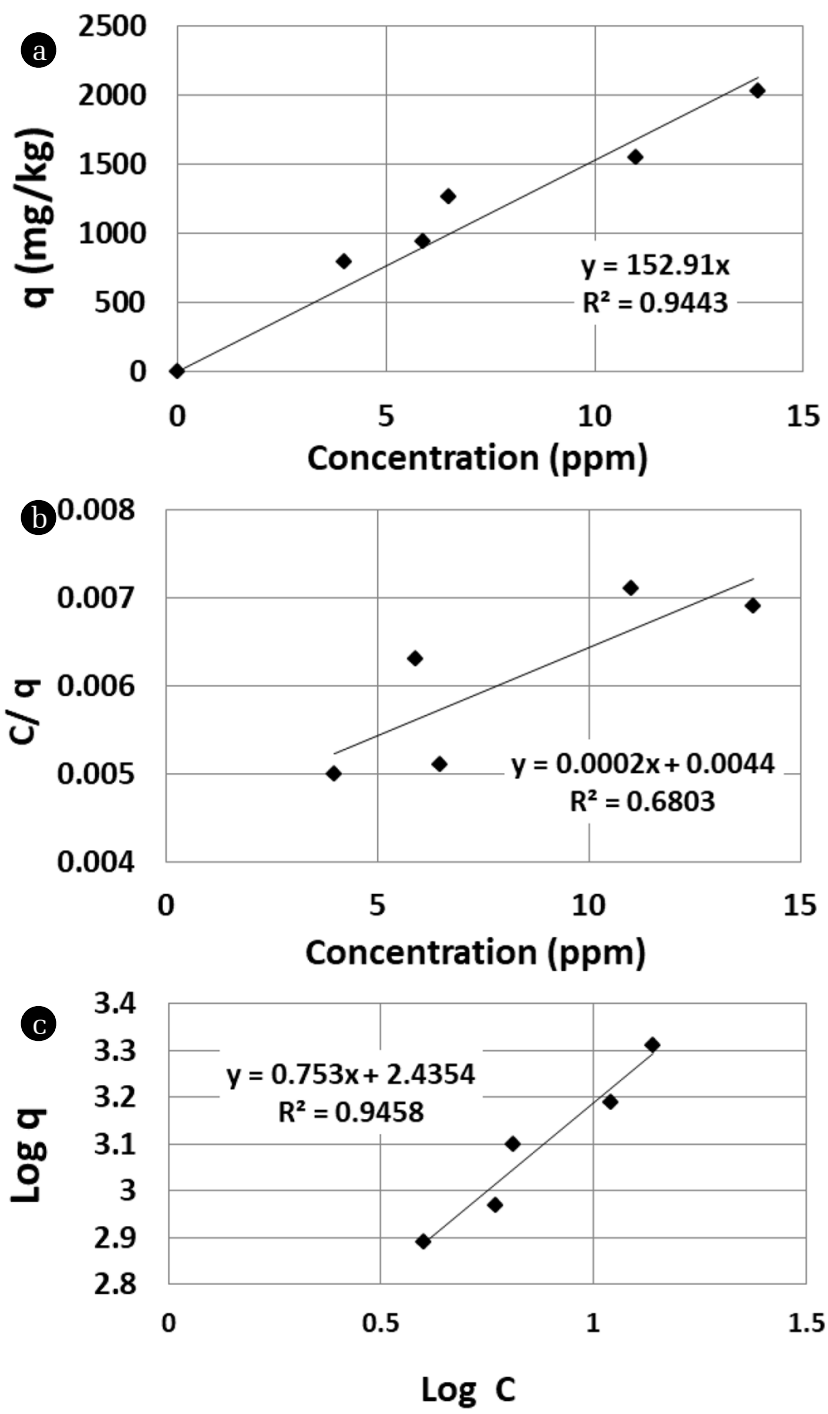

Fig. 1. Adsorption isotherm curves a) linear, b) Langmuir and c) Freundlich.

an appropriate model explaining the removal of high phenol concentration, instead of Freundlich one. It is impossible to introduce a definite isotherm to adsorb phenol considering different circumstances while carrying out the experiment such as, temperature, $\mathrm{pH}$ and different organophilic. However, taken abundant studies

Table 3. Results of Batch Equilibrium Absorption Test

\begin{tabular}{ccccc}
\hline Sample & $\begin{array}{c}\text { Primary mass of phenol in } \\
\text { solution (mg) }\end{array}$ & $\begin{array}{c}\text { Secondary mass of phenol in } \\
\text { solution (mg) }\end{array}$ & $\begin{array}{c}\text { Total adsorbed phenol } \\
\text { (mg) }\end{array}$ & $\begin{array}{c}\mathbf{q}^{\mathbf{a}} \\
(\mathbf{m g} / \mathbf{k g})\end{array}$ \\
\hline 1 & 5 & 0.24 & 4.76 & 793.3 \\
$\mathbf{( p p m )}$
\end{tabular}

\footnotetext{
${ }^{a}$ Total adsorbed phenol (mg) / amount of organophilic clay $(\mathrm{kg})$
} 
conducted on the adsorption isotherm of phenol, Freundlich isotherm has mainly been introduced for the adsorption of phenol.

\subsection{Hydraulic Conductivity}

As shown in Fig. 2, the permeability coefficient of $S_{80} M_{20}$ is 1,000 times greater than $\mathrm{S}_{80} \mathrm{~B}_{20}$. While, when bentonite amount is increased to $30 \%\left(\mathrm{~S}_{70} \mathrm{~B}_{30}\right)$, the permeability coefficient declines around three times in comparison with $\mathrm{S}_{80} \mathrm{~B}_{20}$. It suggests that bentonite increasing over $20 \%$ has only a minor effect on permeability coefficient; because a major part of sand pores has probably been filled due to bentonite swelling. The $\mathrm{S}_{70} \mathrm{~B}_{30}$ is the most impermeable compound. The difference in permeability coefficient in $\mathrm{S}_{80} \mathrm{~B}_{20}$ and $\mathrm{S}_{60} \mathrm{~B}_{20} \mathrm{M}_{20}$ may not be merely due to the presence of organiphilic clay in $\mathrm{S}_{60} \mathrm{~B}_{20} \mathrm{M}_{20}$. It could also be because of the variation in the nature of both clays. In the samples containing bentonite, similar results are also observed in the study of Komine [40], Badv and Ashrafi [1]. Irene [7] pointed out the mixture consist of $20 \%$ bentonite, $20 \%$ organophilic clay, and $60 \%$ sand gain the lowest permeability $\left(10^{-10} \mathrm{~m} / \mathrm{s}\right)$. Irene [7] also reveals that the soil specimen with more organoclays provide higher adsorption capacity. It is also proposed that the presence of bentonite reduces hydraulic conductivity of admixture. The same trend was observed by Jhamnani et al. [2], who obtained the best permeability coefficient $\left(1.6 \times 10^{-10} \mathrm{~m} / \mathrm{s}\right)$ at the same mixing percentage.

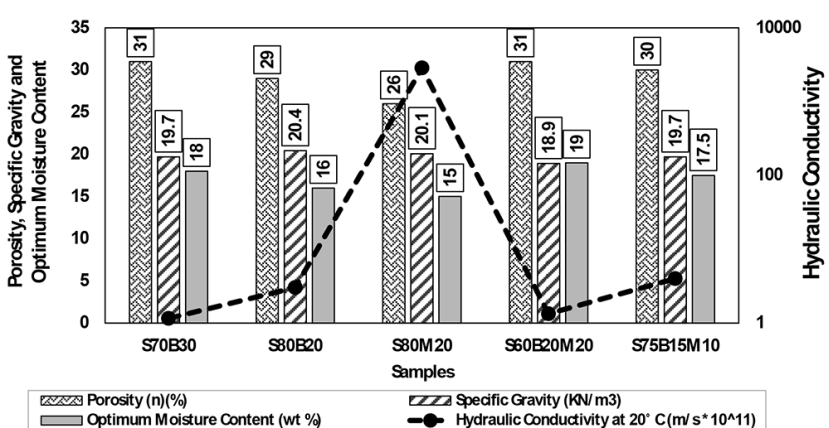

Fig. 2. Physical properties and hydraulic conductivity of the samples.

Various factors can influence hydraulic conductivity, which will also be the cause for different results across different studies. The most important of them are as follows:

- The structure and texture of clay: Komine [40] has stated that swelling of Montmorillonite is one of the major causes of diminished hydraulic conductivity by bentonite. Therefore, the physical properties of soil are a regional function and case dependent [40].

- Compression efforts: Other factors that can influence hydraulic conductivity are proper compression effort on the soil sample which can be effective in reducing permeability due to crushing clay flocs and decreasing soil porosity.

- The type of solution used in the measurement of permeability: Clay minerals are sensitive to chemicals where the presence of some chemicals can affect the clay structure and properties. In various other studies, researchers also examined clays permeability. They explored that solution such as solid waste leachate causes higher permeability in clay. Moreover, the presence of $\mathrm{Ca}^{2+}$ ion can increase hydraulic conductivity. This observation could be attributed to the shrinkage of Montmorillonite structure [41]. In the other researches performed by Irene [7] and Jhamnani [2], the permeability of TOC-contaminated solutions was studied. Their reported permeability coefficients were $0.4 \times 10^{-8}$ and $1.8 \times 10^{-8}(\mathrm{~cm} / \mathrm{s})$, respectively. The difference between the results of these researches and the present study can stem from the fact that different solutions had been applied.

\subsection{Dispersion Coefficient}

The summary of the calculated dispersion coefficients $\left(D_{x}\right)$ and retardation factors (R) for different compounds of sand, bentonite, and organophilic clay is given in Fig. 3. In these compounds, $D_{x}$ varies between $1.85 \times 10^{-10}$ and $7.99 \times 10^{-10} \mathrm{~m}^{2} / \mathrm{s}$. The lower $D_{x}$ shows the lower capability of the contaminant's movement.

Dispersion depends on several factors including ion radius, the ion absolute mobility, temperature, the fluid viscosity, and the ion valance. The role of the soil structure cannot be neglected either. For instance, in soil with fractures in the clay, some pores have been developed whereby it spreads the contaminant [42]. In sites in which their permeability coefficient range forms $10^{-6}$ to $10^{-7} \mathrm{~cm} / \mathrm{s}$, advection is the dominant mechanism. While in sites with lower permeability of $10^{-8} \mathrm{~cm} / \mathrm{s}$, the dispersion phenomenon is influential. As mentioned before, the diffusion coefficient $\left(\mathrm{D}^{*}\right)$ is governing with high diffusion in fine soils. On the other hand, the mechanical dispersion coefficient $\left(\mathrm{D}_{\mathrm{m}}\right)$ is governing with low diffusion in coarse soil [31]. The permeability values (Fig. 2) and the rate of reduction in the concentration of the output contaminant (Fig. 3) confirm that the diffusion phenomenon is the predominant mechanism in the samples of the present study.

The calculated retardation factor ( $R$ ) was also presented in Fig. 3. As shown in the figure, they are relatively high and ranged from 7.45 to 16.63 for the mixtures of $\mathrm{S}_{80} \mathrm{~B}_{20}$ and $\mathrm{S}_{80} \mathrm{M}_{20}$, respectively. Moreover, adding organophilic clay led to suddenly increase in the retardation factor. When $20 \%$ of organophilic clay was replaced with $20 \%$ of bentonite, the retardation factor was significantly increased which makes predictable the considerable descending trend of diffusion factor. This behavior can be explained by the great ability of organophilic clay to adsorb organic compounds. Comparing $D_{x}$ of $S_{80} M_{20}$ (16.63) and $S_{60} B_{20} M_{20}$ (15.58), it can observe that as the organophilic clay percentage increases, the dispersion

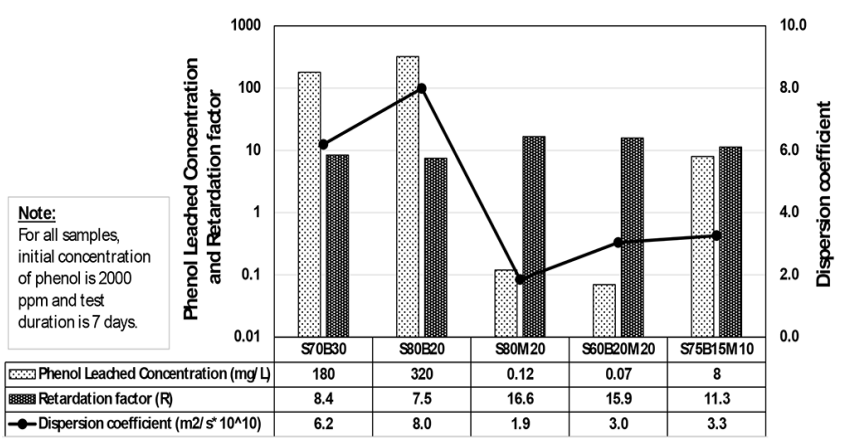

Fig. 3. Dispersion coefficient, phenol leached concentration and retardation factor of the samples.

coefficient decreases. Furthermore, taking the adsorption capacity 
Table 4. Equations Chosen Function Permeability, the Leakage of Phenol and Cost in This Study

Formula of permeability (k)

Formula of phenol leakage (C)

Formula of price (P)

$$
\begin{aligned}
& 1 / \mathrm{k}=-0.468+0.0415 \mathrm{~B}+0.0200 \mathrm{M}, \mathrm{R}^{2}=95.3 \% \\
& \ln (\mathrm{C})=6.48-0.421 \mathrm{M}-0.0366 \mathrm{~B}, \mathrm{R}^{2}=99.7 \% \\
& \mathrm{P}=(0.60 \times \mathrm{B})+(2.675 \times \mathrm{M})
\end{aligned}
$$

of bentonite for samples sand $S_{80} B_{20}$ and $S_{70} B_{30}$, reduction in dispersion coefficient is expected. Eventually, the $S_{60} B_{20} M_{20}$ with the highest adsorption level succeeded in obtaining the lowest dispersion coefficient, thereby introducing itself as the best compound in terms of dispersion.

\subsection{Cost Analysis to Find the Best Combination}

Table 4 shows the applied functions for optimizing of the used materials. The objective is minimizing of "P" function. Moreover, two other constraint functions were added in order to limit the amount of used materials; bentonite less than $30 \%$ and organophilic less than $20 \%$. The results showed that a combination including $10.2 \%$ bentonite and $2.8 \%$ organophilic clays has the best one to minimize the cost. This combination has a permeability of $10^{-9}$ $\mathrm{m} / \mathrm{s}$, phenol leakage of $137 \mathrm{mg} / \mathrm{L}$, and cost of $13.64 \$ /$ ton.

\section{Conclusions}

This research has been conducted to investigate the geo-environmental properties of different compounds of sand, bentonite and organophilic clays with emphasis on permeability and adsorption characteristics. In the batch equilibrium test, the adsorption isotherm of organophilic clay for phenol indicated the greatest correspondence with the nonlinear Freundlich isotherm. The sample containing $30 \%$ bentonite gains the lowest permeability coefficient. Although it was observed that bentonite has played a major role in reducing permeability to meet all environmental criteria in order to prevent from contamination leakage the permeability alone is insufficient. Therefore, the adsorption capacity in mixes was further investigated. The sample of $20 \%$ organophilic and $80 \%$ sand is introduced as the best phenol adsorbent, because it produces the greatest retardation factor (16.63) as well as the lowest dispersion coefficient. The result of the present study suggests that bentonite and organophilic clays have a large influence on reducing permeability and increase adsorption efficiency, respectively. Therefore, the mixture with $60 \%$ sand, $20 \%$ organophilic clay, $20 \%$ bentonite meets all acceptable standards for the landfill liner and thus is established as the best compound among the samples. To achieve better results, the best option for adsorption of organic contaminants can be chosen by examining other different modifying factors. Moreover, better results can be obtained in permeability and adsorption by changing the mix design. In order to reach the optimal composition with respect to economy and performance, the evaluation of material cost and executive operation condition was made. The optimization provides the optimum composition with $10.2 \%$ of bentonite and $2.8 \%$ of organophilic clays which has a permeability of $10^{-9} \mathrm{~m} / \mathrm{s}$, phenol leakage of $137 \mathrm{mg} / \mathrm{L}$, and cost of $13.64 \$ /$ ton. Although the use of organophilic clay might appear not to be economical, it should be noted that the costs expended for running the projects against environmental damages which will be irrecoverable in the future can be considered trivial.

\section{Acknowledgments}

The authors of this research highly acknowledge the financial support of National Iranian Oil Refining and Distribution Company.

\section{References}

1. Badv K, Ashrafi H. Laboratory evaluation of geotechnical and geoenvironmental properties compounds sand-bentonite for use in liner of landfills. Civil Environ. Eng. J. 2015;45:13-23.

2. Jhamnani B, Singh SK. Evaluation of organoclays for use in landfill liners. Open Waste Manage. J. 2009;2:37-42.

3. Abolfazlzadeh M, Ardeshir A, Hussein Pour MA, Khamsei B. Ordinary bentonite clay structures and the modification process. In: Conference of Environmental Engineering; 2009; Tehran, Iran. p. 1-7.

4. Cadena F. Use of tailored bentonite for selective removal of organic pollutants. J. Environ. Eng. 1989;115:756-767.

5. Daniel D. Earthen liners for land disposal facilities. In: Geotechnical Practice for Waste Disposal '87. Woods RD, eds. ASCE; 1987. p. 21-39.

6. Gitipour S, Bowers M, Huff W, Bodocsi A. The efficiency of modified bentonite clays for removal of aromatic organics from oily liquid wastes. Spill Sci. Technol. Bull. 1997;4:155-164.

7. Irene MC. Organoclay with soil-bentonite admixture as waste containment barriers. J. Environ. Eng. 2011;127:756-759.

8. Sharafi M, Bazgir S. Adsorption of petroleum hydrocarbons on organoclay. J. Adv. Sci. Res. 2010;4:19-23.

9. Abdelwahab E. Modified activated carbon and bentonite used to adsorb petroleum hydrocarbons emulsified in aqueous solution. Am. J. Environ. Prot. 2013;2:161-169.

10. Guddada MK, Benabed B, Taibi S, Aboubakr N. Hydraulic properties of dune sand-bentonite mixtures of insulation barriers for hazardous waste facilities. J. Rock Mech. Geotech. Eng. 2016;8:541-550.

11. Sarkar B, Xi Y, Mallavarapu M, Krishnamurti GSR, Naidu R. Adsorption of phenol by HDTMA-modified organoclay. 19th World Congress of Soil Science; 1-10 August 2010; Australia.

12. Sharafi M, Bazigar S, Tamizifar M, Nemati A. Adsorption of hydrocarbons on modified nanoclays. IOP Conference Series: Materials Science and Engineering 18; 2011; Symposium 12.

13. Zhao Q, Choo H, Bhatt A, Burns SE, Bate B. Review of the fundamental geochemical and physical behaviors of organoclays in barrier applications. Appl. Clay Sci. 2017;142:2-20.

14. Javadi S, Ghavami M, Zhao Q, Bate B. Advection and retardation of non-polar contaminants in compacted clay barrier material 
with organoclay amendment. Appl. Clay Sci. 2017;142:30-39.

15. Gitipour S, Hosseinpour MA, Heidarzadeh N, Yousefi P, Fathollahi A. Application of modified clays in geosynthetic clay liners for containment of petroleum contaminated sites. Int. J. Environ. Res. 2015;9:317-322.

16. Zhu R, Zhou Q, Zhu J, Xi Y, He H. Organo-clays as sorbents of hydrophobic organic contaminants: Sorptive characteristics and approaches to enhancing sorption capacity. Clays Clay Miner. 2015;63:199-221.

17. Heidarzadeh N. Solidification/stabilization of polycyclic aromatic hydrocarbons in soil using organophilic clay and cement [dissertation]. Tehran: Tehran Univ. College of Environment; 2010.

18. Mirmohammadi N. Laboratory investigation thermomechanical of saturated clay soils structure at high temperatures [dissertation]. Tehran: Kharazmi Univ. College of Engineering; 2015.

19. MERCK, c2016 [cited 18 November 2016]. Available from: http://www.merckmillipore.com/.

20. Hosseinpur MA. Improvement efficiency geosynthetic clay liners (GCL) against hydrocarbon contaminants using organophilic clays [dissertation]. Tehran: Tehran Univ. College of Environment; 2008.

21. Mitchell JK. Fundamental of soil behavior. New York: John Wiley \& Sons, Inc.; 1976.

22. U.S. EPA. Adsorption-Desorption using a batch equilibrium method. OECD Guideline for the Testing of Chemicals; 2000.

23. Chen X. Modeling of experimental adsorption isotherm data. Inf. J. 2015;6:14-22 (China).

24. U.S. EPA. Method 420.1: Phenolics (Spectrophotometric, Manual 4AAP with Distillation); 1978.

25. ASTM. Standard test method for measurement of hydraulic conductivity of porous material using a rigid-wall compaction-mold permeameter, Method D5856-95, West Conshohocken (PA): ASTM International; 1996.

26. ASTM. Measurement of hydraulic conductivity of saturated porous materials using a flexible-wall permeameter, Method D5084-03, West Conshohocken (PA): ASTM International; 2003.

27. Trainor DP. Moisture and saturation effects on hydraulic conductivity testing. Proc. $9^{\text {th }}$ Annu. Madison Conf. App. Res. Pract. Munic. Waste. (WI): Univ. of Wisconsin Extension; 1986. p. 646-657.

28. U.S. EPA. Saturated hydraulic conductivity, saturated leachate conductivity, and intrinsic permeability. Method 9100, revision $0 ; 1986$.

29. Sarsby RW, Heggie IS, Rainford S. Permeability measurements in the triaxial apparatus. Proceedings of the Symposium Green'93: Geotechnics Related to the Environment. Bolton: Balkema; 1995.

30. Roque AJ, Didier G. Calculating hydraulic conductivity of fine-grained soil to leachates using liner expressions. J. Eng. Geol. 2005;851:147-157.

31. Reddi L, Inyang H. Geoenvironmental engineering: Principles and applications. New York: Marcel Dekker, Inc.; 2000.

32. Taslimi T. Solidification/stabilization of phenol in soil using organophilic clay and white cement [dissertation]. Tehran: Kharazmi Univ., College of Engineering; 2016.

33. U.S. EPA. Design, construction and evaluation of clay liners for waste management facilities. In: Goldman JD, Greenfield LI, Damle AS, Kingsbury GL, Northeim CM, Truesdale RS, eds. 2007; Cincinnati $(\mathrm{OH})$.

34. U.S. EPA. Subtitle C-Identification and listing of hazardous waste. In: Goldman JD, Greenfield LI, Damle AS, Kingsbury GL, Northeim CM, Truesdale RS, eds. 2 May 2007; Cincinnati $(\mathrm{OH})$.

35. Belarbi H, Al-Malack MH. Adsorption and stabilization of phenol by modified local clay. Int. J. Environ. Res. 2010;4:855-860.

36. Froehner S, Fernandes R, Furukawa W, Risso M. Water remediation by adsorption of phenol onto hydrophobic modified clay. Water Air Soil Pollut. 2009;199:107-113.

37. Maarof H, Hameed B, Ahmad AL. Adsorption equilibrium of phenols from aqueous solution using modified clay. J. Jurutera Kimia Malaysia 2003;3:85-96.

38. Banat AF, Bashir B, Asheh S, Hayajneh O. Adsorption of phenol by bentonite. Environ. Pollut. 1999;107:391-398.

39. Djebbar M, Djafri F, Bouchekara M, Djafri A. Adsorption of phenol on natural clay. Appl. Water Sci. 2012;2:77-86.

40. Komine H. Simplified evaluation on hydraulic conductivities of sand-bentonite mixture backfill. Appl. Clay Sci. 2002;26:13-19.

41. Madsen FT, Mitchell JK. Chemical effects on clay fabric and hydraulic conductivity. In: Lecture notes in earth sciences, volume 20: The landfill, reactor and final storage. Baccini P, eds. Berlin: Springer-Verlag; 1989. p. 201-251.

42. Yong RN. Geoenvironmental engineering. Contaminated soils, pollutant fate and mitigation. 1st ed. New York: CRC Press; 2000 . 